\title{
LAS CARTAS DE PROFESIÓN DEL MONASTERIO DE SANTA PAULA DE SEVILLA
}

\section{THE VOCATION LETTERS OF THE MONASTERY OF SANTA PAULA IN SEVILLE}

\author{
Rosario Marchena Hidalgo \\ Universidad de Sevilla. España \\ romahi@us.es
}

\begin{abstract}
Desde su fundación, el monasterio de Santa Paula ha ido acumulando un patrimonio documental, prácticamente intacto, formado por más de 480 cartas de profesión fechadas entre 1475 y 1942 de las que unas 180 están iluminadas. Algunas de ellas manifiestan una clara relación con conocidos talleres miniaturistas sevillanos.

Palabras clave: monasterio de Santa Paula; comunidad jerónima; hábito; cartas de profesión; iluminación.
\end{abstract}

The Monastery of Santa Paula in Seville has accumulated a documentary heritage since its establishment. It is currently intact and made up of more than 480 vocation letters dated between 1475 and 1942, of which about 180 are illuminated. Some of them show a clear relationship with most renowned Sevillian miniaturist workshops of their time.

Keywords: Monastery of Santa Paula; Jerome community; habit; vocation letters; illumination.

\section{INTRODUCCIÓN}

La orden jerónima surge en España y Portugal en el siglo XIV con la sede central en el monasterio de San Bartolomé de Lupiana (Guadalajara). El primer monasterio femenino de jerónimas se funda en 1374 en Santa María de Sisla (Toledo) y, 100 años después, Ana de Santillán y Guzmán, que vivía en el beaterio de San Juan de la Palma, concibe el proyecto de fundar un monasterio jerónimo en 
Sevilla ${ }^{1}$. Tras conseguir la bula fundacional en 1473 de manos de Sixto IV, se traslada el 7 de julio de 1475, junto a otras trece compañeras más, a unas casas de su propiedad en la collación de San Román que se ampliaron con otras de la de San Marcos compradas al monasterio de San Jerónimo de Buenavista. Unos días después, el 13 de julio, Ana de Santillán y las otras beatas firman su carta de profesión tomando el hábito, blanco y pardo, de la orden jerónima. En este germen del monasterio de Santa Paula vivirán estas 14 mujeres, a las que se fueron sumando otras en los años siguientes, dedicadas a la vida contemplativa, en perpetua clausura, bajo la regla de San Agustín y con constituciones propias. Esta es la vida en la que ingresan las novicias para acomodarse al convento que va a ser su casa de por vida. Generalmente al año del ingreso se realiza la profesión que ya la convierte en un miembro pleno de la comunidad. La normativa que regula las condiciones de ingreso en el convento está fijada por el Concilio de Trento y recogida en un libro de 1575.

"Primeramente que ninguna Monja haga profesión antes de diez y seis años cumplidos de su edad y un Año cumplido de provación, y la profesión fecha antes, sea de Ningún valor.

Ytem si tomase el hábito cumplidos doze Años que no se lo den sin primero sea examinada por El Ordinario, si lo quiere tomar de voluntad y si entiende qué es lo que toma.

Ytem cuando el ordinario preguntase a la Novicia que quiere hacer profesión no pueda entrar en el Monesterio, mas desde la rexa le hable, y no le a de preguntar Más de lo que el santo Concilio manda, Que es si sabe lo que haze y si es compelida o engañada. Para ello y no más"2.

Las novicias deben tener quince años para ingresar en el convento y dieciséis cumplidos a la hora de profesar, y, si se ha hecho con menos edad, no debe tener valor. Pero hay quien toma el hábito con doce y se admite su entrada si previamente la niña dice que lo toma voluntariamente y que entiende lo que está haciendo. Las mismas preguntas y no más le hace el ordinario desde la reja a la novicia que va a profesar.

Además de las novicias y las profesas, en el monasterio vivían las criadas de ambas y las legas, cuyo número osciló a lo largo del tiempo. Santa Paula solicitó con frecuencia recibir monjas cantoras y tañedoras sin dote, lo que el capítulo general de la orden solía denegar o restringir en el tiempo ${ }^{3}$. Estas monjas eran

${ }^{1}$ Mi agradecimiento a toda la comunidad de Santa Paula y muy especialmente a su priora sor Tyama, a sor Mari Cuñi y a sor Marta por las facilidades dadas para la elaboración de este trabajo.

2 Archivo del Monasterio de Santa Paula de Sevilla (A.M.S.P.S.), Régimen y Gobierno, Profesiones, lib. 14.

3 SÁNCHEZ LÓPEZ, Gustavo: "La música en los monasterios de monjas jerónimas a la luz de las Actas Generales de la Orden", en CAMPOS Y FERNÁNDEZ DE 
imprescindibles para celebrar las fiestas pues el monasterio tenía prohibido contratar músicos, tanto seglares como religiosos y, desde luego, que estos entraran en clausura ${ }^{4}$.

El monasterio de Santa Paula, como todos los de las jerónimas que dependen siempre de uno masculino de la misma orden, está tutelado de forma explícita por el de San Jerónimo de Buenavista, lo que deja claro la carta de profesión de la fundadora en la que, tras prometer obediencia a Dios, a la Virgen y a San Jerónimo, lo hace a fray Juan de Ortega, general de la orden, y a fray Juan de Sevilla, vicario del monasterio de San Jerónimo, cuyo prior en ese momento es fray Pedro de Burgos 5 .

La economía del convento descansaba sobre las rentas que le proporcionaban sus propiedades pero también sobre inversiones de las que queda un pequeño rastro documental, como el de los juros a favor del monasterio de 53.571 maravedís de la segunda mitad del siglo XIX y de 223.363 de la primera mitad del XVII ${ }^{6}$, o la carta de pago por 283.200 maravedís de réditos de censos que otorgó en 1619 María Díez de Vergara, priora del monasterio, al noble, vecino de Sevilla, Juan de Hinestrosa, Cárdenas, Ribera y Cerón ${ }^{7}$. Muy importantes fueron también las donaciones y mandas testamentarias no siempre respetadas por los familiares del difunto. Gonzalo Ruiz de Córdoba dejó unas mandas a favor de las profesas del monasterio, Inés de San Jerónimo y Beatriz de Santander, que no se respetaron por parte de su viuda Beatriz de la Sal y sus hijos, por lo que la priora y las monjas las reclaman en $1568^{8}$. Algunos de los escasos documentos que hay del monasterio se refieren a su participación de los recursos de la ciudad, como dos concesiones, de 1498 y 1500, de agua de los Caños de Carmona 9 .

Sucesivas adquisiciones crearon un espacio de grandes dimensiones en el que hay todos los elementos necesarios en un convento de clausura femenino: iglesia, sacristía, claustros, refectorio, celdas, etc. La disminución mayor de su espacio la han sufrido las huertas en las que se levantaron sobre ellas, previamente desamortizadas, las naves industriales del Pasaje Mallol a fines del siglo XIX. Desde su fundación la vida monástica en Santa Paula no se ha interrumpido nunca hasta

SEVILLA, Francisco Javier (coord.): Actas del congreso La clausura femenina en el mundo hispánico: una fidelidad secular. San Lorenzo de El Escorial, 2011, pp. 945-958 (957).

${ }^{4}$ Ibidem, pp. 953-954.

5 A.M.S.P.S., Régimen y Gobierno, Profesiones, leg. 2.

${ }^{6}$ Archivo General de Simancas (A.G.S.), Cancillería, Registro del Sello de Corte, sig. CME, 468, 5 y CME, 783, 10.

7 Archivo Histórico Nacional (A.H.N.), sección Nobleza. 51. Archivo de los Marqueses de Guadalcázar, sig. C.12, D. 27.

8 Archivo General de Indias (A.G.I.), Justicia, 801, N. 1.

9 A.G.S., Cancillería, Registro del Sello de Corte, sig. R.G.S., leg. 149803, 114 y 150006, 5 . 
nuestros días, pese a haber pasado momentos verdaderamente difíciles, unos externos -la ocupación francesa, el bombardeo de Sevilla de 1843, la Segunda República, la Guerra Civil, etc.- y otros internos -la disminución de los recursos económicos y del número de profesas-, que dificultan la atención a su gran patrimonio cultural, artístico y documental. El que ha ido acumulando a lo largo de los casi 550 años de su vida, salvo ocasionales saqueos, se ha mantenido y se ha visto incrementado por la colección artística donada por sor Cristina de Arteaga, heredada de sus padres, los duques del Infantado. Los estudios que se han hecho han recaído principalmente sobre el aspecto artístico del monasterio, pero la atención sobre su patrimonio documental ha sido escasa, como ocurre con toda la comunidad jerónima femenina ${ }^{10}$.

\section{CARTAS DE PROFESIÓN DEL MONASTERIO DE SANTA PAULA}

El monasterio de Santa Paula conserva las actas de profesión, que recogen la vinculación de las monjas al convento, en siete libros que van desde 1608 a $1955^{11}$ y, además, prácticamente todas las cartas de profesión desde su fundación hasta la mitad del siglo XX. Las más antiguas, sueltas, están reunidas en un legajo que abarca desde 1475 hasta $1574^{12}$. Son 98 en total y se inician con la de la misma fundadora, Ana de Santillán y sus 13 compañeras (13-VII-1475). Son cartas dispares en cuanto al material, pues las hay de vitela, tan fina que bien podría ser piel de conejo, como la de Justa de los Ángeles, una de las fundadoras, y las hay de papel como la de Jerónima de Santa Inés (25-VIII-1567). También difieren en el tamaño, que oscila desde los 140 x $190^{13}$ y los 440 x $315^{14} \mathrm{~mm}$, y en el formato, aunque son mayoritariamente apaisadas. No están decoradas, sino escritas con letras muy homogéneas en tinta negra, salvo alguna capital en roja.

A partir de 1575 se estableció que las cartas fueran encuadernadas para evitar que se perdieran, como ya había sucedido con anterioridad: "Las religiosas

${ }^{10}$ MARCHANT RIVERA, Alicia y BLANCO CEBRIÁN, Lorena: "Las Jerónimas de San Pablo de Toledo en la sección Clero del Archivo Histórico Nacional: mujer, escritura y producción documental", en Actas de las XI Jornadas Cientificas de la Sociedad Española de Ciencias y Técnicas Historiográficas, Lugares de Escritura: el monasterio. Alicante, 2013, pp. 349-360 (350).

${ }_{11}$ A.M.S.P.S., Régimen y Gobierno, Profesiones, libs. 7, 8, 9, 10, 11, 12 y 13, Actas de Profesión.

12 A.M.S.P.S., Régimen y Gobierno, Profesiones, leg. 2.

${ }_{13}$ Leonor de los Ángeles (3-II-1502). A.M.S.P.S., Régimen y Gobierno, Profesiones, leg. 2.

${ }^{14}$ Ierónima de Santa Ynés (25-VIII-1567). A.M.S.P.S., Régimen y Gobierno, Profesiones, leg. 2. 
que professasen de aquí en adelante asentarán aquí las cartas poniendo día, mes y año en que hacen la professión como parece en la primera carta de professión que en este libro va puesta a la vuelta desta hoja que es de Ana de San Gabriel y a las que hasta aquí van escritas no se le puso año, día y mes en que professaron porque al tiempo que aquí se escribieron no parecieron algunas cartas y por esto se hizo este libro porque las que aquí en adelante se escribieran se guarden con más recaudo". Así se dice en el primero de los cuatro libros en que se recogen las cartas de profesión, que es el $14^{15}$. Éste abarca desde 1575 a $1618^{16}$; el 15 , desde 1618 hasta $1641^{17}$; el 16 , desde 1642 a 1790 , pese a lo que se dice en el folio de guarda delantero ${ }^{18}$; y el último, el 17, desde diciembre de 1790 a $1942^{19}$. Los cuatro libros, de papel, realizados en cuarto menor, tienen un tamaño muy semejante ${ }^{20} \mathrm{y}$ han cumplido el objetivo previsto, evitar la desaparición de las cartas de profesión, al imponer la obligatoriedad de encuadernarlas. Este mandato homogeneizó, en cuanto al material, al tamaño y al formato, pues éstas son verticales de ahí en adelante. Además, salvo una sola excepción, las cartas van ordenadas cronológicamente, lo que facilita de forma sustancial su estudio pudiéndose establecer a través de las fechas la evolución, principalmente, de sus ilustraciones.

La conservación de las cartas más antiguas, de 1475 a 1574, es bastante buena, aunque tienen unos pliegues ortogonales que formaron cuadrados de 8-10 centímetros cuya función sería llevarlas encima como si de un escapulario se tratase. Algo peor están las de los años siguientes, pues en los cuatro libros que las contienen, con frecuencia la tinta ha corroído el papel, haciendo que trozos o cartas enteras se desprendan. Algunas de ellas están tachadas ${ }^{21}$,

15 A.M.S.P.S., Régimen y Gobierno, Profesiones, libs. 14, 15, 16 y 17, Cartas de profesión.

16 A.M.S.P.S., Régimen y Gobierno, Profesiones, Libro de professiones. De las Monjas deste Monesterio de Nuestra Madre Santa Paula. De la orden de nuestro padre Sanct Hierónymo.

17 A.M.S.P.S., Régimen y Gobierno, Profesiones, Este libro es de las Professiones que hacen las monjas de este monasterio de Santa Paula de Sevilla desde principios del año 1618 en adelante.

18 A.M.S.P.S., Régimen y Gobierno, Profesiones, Contiene 167 cartas. Estas son del 1600 al 1700.

19 A.M.S.P.S., Régimen y Gobierno, Profesiones, Libro de Cartas de Profesión de este Monasterio de Nuestra Madre Santa Paula de esta ciudad de Sevilla; se hizo siendo Priora mi Señora Doña Bernardina de Cárdenas y Gonzales y Arquera la Señora Doña María de Molina y Zuleta; en este presente año de 1790.

${ }^{20}$ Libro 14, 24 x $18 \mathrm{~cm}$; libro 15, 24,2 x 17,2 cm; libro 16, 25 x 17,5 cm; y libro 17, 25 $\mathrm{x} 18 \mathrm{~cm}$.

${ }^{21}$ A.M.S.P.S., Régimen y Gobierno, Profesiones, lib. 16, p. 49. 
seguramente por muerte de la profesa, e incluso una está medio arrancada ${ }^{22}$. En el libro 14, los márgenes inferiores de las páginas donde iban las firmas de las profesas han sido cortados y posteriormente reconstruidos con un trozo de papel en el que se ha escrito de nuevo su nombre. Una inscripción necrológica en la que se dice que se prendió en el hábito y escapulario de la difunta un trozo de pergamino con su nombre ${ }^{23}$, nos hace suponer que estos recortes se debieron al uso que se hizo de este trozo de papel para identificar el cadáver de la profesa. Pero indudablemente el daño mayor que han sufrido las cartas es la desaparición de algunas de ellas. Ya se dice esto de las cartas de los 100 primeros años para explicar por qué se van a encuadernar desde 1575. Mucho más relevante es la enajenación de la que ocupaba la página 141 del libro 16, en cuyo makulatur trasero una nota a lápiz dice: "La carta de profesión de Petronila de San Pedro está firmada por el famoso pintor Cornelio Schut y es de relevante Mérito. R”. Esa valoración fue la sentencia de muerte de la carta como aclara una nota suelta de la vicaria y priora sor Aurora de Santa María, en el mundo Carrerano: "En el año 1977 comprobamos que esta carta ha sido arrancada; ¿por quién? No sabemos. Parece que Gestoso la tiene registrada y es la última noticia que se tiene". Efectivamente, Gestoso recoge su autoría, aunque existe una contradicción en el nombre de la propietaria: "[...] en el libro de cartas de profesiones de las religiosas de Santa Paula de esta ciudad correspondientes a las del siglo XVII, y en la de Petronila de San Miguel, hija de Don Miguel de Usarte, que es una preciosa aguada. Se ve la firma -Schutt-Pincit-F. Dicha carta lleva la fecha de 1682"24. Su ejecución se realizó entre las cartas de Ana de la Concepción, 15 de octubre de 1682, y Bernardina del Santísimo Sacramento, 14 de junio de $1683^{25}$.

En el número de las cartas recogidas en estos cuatro libros se observa una variación, pues hay 98 desde 1475 hasta un siglo después, 44 correspondientes al último cuarto del siglo XVI, por lo que son 142, 163 del XVII, 82 del XVIII, 75 del XIX y 21 del XX. A partir del aumento de profesiones en el siglo XVII se aprecia una disminución progresiva que ilustra la reducción que han venido sufriendo las vocaciones, especialmente en los últimos tiempos: en 1575 vivían en el monasterio 57 profesas $^{26}$; ya a finales del siglo XVII se hace muy evidente esa disminución

${ }^{22}$ A.M.S.P.S., Régimen y Gobierno, Profesiones, lib. 14, s. f.

${ }^{23}$ A.M.S.P.S., Régimen y Gobierno, Profesiones, lib. 17, f. $21 \mathrm{v}$.

${ }^{24}$ GESTOSO Y PÉREZ, José: Ensayo de un Diccionario de los artífices que florecieron en esta ciudad de Sevilla desde el siglo XIII al XVIII inclusive. T. II. Sevilla, 1899-1909, p. 104.

${ }^{25}$ A.M.S.P.S., Régimen y Gobierno, Profesiones, lib. 16, pp. 139 y 143.

${ }^{26}$ Año de mil y quinientos y setenta y cinco vivían en Santa Paula las monjas profesas infraescritas por su antigüedad y años de religión. A.M.S.P.S., Régimen y Gobierno, Profesiones, lib. 14, ff. 2r-v y 3 r. 
por el hecho de que entre las profesiones de María de Santa Clara (22-II-1693) y de María de las Mercedes (5-X-1710) transcurran más de 16 años ${ }^{27}$; en 1798 la comunidad se compone de 45 monjas profesas y seis novicias ${ }^{28}$; en 2009 el número se reduce a 31 y en estos días son 23 , con tendencia a seguir disminuyendo, pues la comunidad está muy envejecida. Santa Paula no es un caso excepcional, habiendo algún otro verdaderamente dramático como es el del monasterio jerónimo de Santa Marta de Córdoba, en donde no queda más que una profesa.

Estas cartas de profesión, escritas en castellano desde el principio, siguen una fórmula idéntica a lo largo del tiempo, establecida ya en la de la fundadora y que no tiene más variantes que la de la evolución del castellano: "Yo, Ana de San Gabriel [...] hago profesión y prometo obediencia a Dios y a Santa María y al bienaventurado Nuestro Padre San Gerónimo y al muy reverendo padre Fray Juan de Yuste general de la orden [...] y a sus sucesores y a vos la Reverenda Madre Francisca de los Reyes, priora deste monasterio de Santa Paula de Sevilla de la orden de ese mismo santo y a sus sucesoras y a vivir sin propio y en castidad según la regla de San Agustín y de guardar perpetua clausura en este dicho monasterio (excepto la obediencia) hasta la muerte. 24 de octubre de $1575^{\prime 2}$. Las cartas de profesión llevan dos firmas: la del visitador o su delegado, cuyo nombre no se recoge, y la de la profesa. En el caso citado únicamente lleva la de fray Alonso de Santa Cruz - "por ausencia de mi prior firmé yo que me hallé presente"-. La inmensa mayoría de las veces existe la firma de la monja, siendo casi una excepción que se diga que no sabía firmar, como ocurre con Francisca de San Jerónimo $(11-\mathrm{X}-1637)^{30}$. Los nombres de las profesas no van precedidos por ninguna titulación, pues hasta muy avanzada la segunda mitad del siglo XIX no aparece "sor" delante de su nombre.

Estas cartas aportan una valiosa información sobre la vida monástica al recoger los nombres religiosos de las profesas, la orden con la que se comprometen, la regla que siguen, la de San Agustín, el monasterio donde profesan, Santa Paula, y los cuatro votos: obediencia a Dios, a la Virgen, a San Jerónimo, al general de la orden, al prior del monasterio de San Jerónimo de Buenavista o al visitador de la orden sucesivamente, cuyos nombres se consignan, a la priora de ese momento, cuyos datos también quedan reflejados en el documento, y a sus sucesores; pobreza; castidad y perpetua clausura.

27 A.M.S.P.S., Régimen y Gobierno, Profesiones, lib. 16, pp. 151 y 153.

${ }_{28}$ PASTOR, Álvaro: "El monasterio sevillano de Santa Paula en el primer tercio del siglo XIX”, en CAMPOS Y FERNÁNDEZ DE SEVILLA, Francisco Javier (coord.): Actas del simposium La clausura femenina en España. Vol. 2. San Lorenzo de El Escorial, 2004, pp. 1367-1392.

${ }_{29}$ A.M.S.P.S., Régimen y Gobierno, Profesiones, lib. 14, f. 3v.

30 A.M.S.P.S., Régimen y Gobierno, Profesiones, lib. 15, f. 58r. 
Pero las cartas de profesión no recogen únicamente los aspectos referidos a la vida monástica, sino otros personales de la monja, principalmente el nombre de sus padres y, a veces, aunque con el dato anterior ya no sería necesario, su propio nombre en el siglo, lo que empieza a aparecer al inicio del último tercio del siglo $\mathrm{XVII}^{31}$. Esto nos permite verificar un hecho que se da en otros cenobios, como en San Clemente de Sevilla o Santa Ana de Málaga, y es la profesión de varias hermanas en el mismo convento. Son hermanas Beatriz de Sancta Ynés (12X-1505) e Ynés de Sant Pedro (28-VI-1534) ${ }^{32}$, Teresa de Jesús (23-XII-1669) y Mariana de San Diego (13-X-1671) ${ }^{33}$, Flor Margarita de San José (29-X-1674) y Susana de San Agustín (21-IV-1678) ${ }^{34}$. Algunas de estas hermanas de sangre llegan incluso a hacer su profesión solemne juntas, el mismo día: Jerónima de Santa Ana y Catalina de San Francisco (5-II-1562) ${ }^{35}$, Francisca de San Diego y Ángela de San Pablo (6-X-1594) ;6 $^{36}$ Gerónima de San Juan y Ana de la Asunción (5-XII-1639) ${ }^{37}$ o Isabel de San Diego y Mariana de San Pedro (28-VIII-1641) ${ }^{38}$, lo que no son hechos aislados, porque casos semejantes los encontramos también en otros monasterios.

Los nombres, títulos y oficios de los padres de las monjas nos aportan información sobre la composición social de los miembros del monasterio. Don Juan Puertocarrero, II conde de Medellín, tuvo dos hijas en el monasterio: Beatriz de Sancta Ynés (12-X-1505) e Ynés de Sant Pedro (8-VI-1524) ${ }^{39}$. Don Álvaro Manrique de Zúñiga y Sotomayor, marqués de Villamanrique, que tuvo otros hijos religiosos, Pedro, de la orden de San Agustín, y Beatriz, profesa del convento de Regina Angelorum de Sevilla, es el padre de Leonor de la Cruz (23-VIII$1581)^{40}$. También aparecen profesionales, como el bachiller Morales o el doctor Santander, padres de Leonor de San Felipe y Ana de Santiago respectivamente, que profesaron el mismo día $(8-\mathrm{V}-1547)^{41}$, o artistas como el escultor y retablista Francisco Dionisio de Ribas, padre de Ana de la Concepción (15-X-1682) ${ }^{42}$. Muchas familias relevantes en el mundo sevillano, en muy distintos ámbitos, se reconocen en los nombres del siglo de las profesas de Santa Paula. En otros tipos de documentos se recogen, a veces, relaciones de las profesas con miembros de la

31 A.M.S.P.S., Régimen y Gobierno, Profesiones, lib. 16, p. 63.

32 A.M.S.P.S., Régimen y Gobierno, Profesiones, leg. 2.

A.M.S.P.S., Régimen y Gobierno, Profesiones, lib. 16, pp. 85 y 91.

A.M.S.P.S., Régimen y Gobierno, Profesiones, lib. 16, pp. 101 y 115.

A.M.S.P.S., Régimen y Gobierno, Profesiones, leg. 2.

A.M.S.P.S., Régimen y Gobierno, lib. 14, s. f.

A.M.S.P.S., Régimen y Gobierno, Profesiones, lib. 15, ff. 61v y 62 r.

A.M.S.P.S., Régimen y Gobierno, Profesiones, lib. 15, ff. 67v y $68 \mathrm{r}$.

39 A.M.S.P.S., Régimen y Gobierno, Profesiones, leg. 2.

40 A.M.S.P.S., Régimen y Gobierno, Profesiones, lib. 14, s. f.

${ }^{41}$ A.M.S.P.S., Régimen y Gobierno, Profesiones, leg. 2.

${ }^{42}$ A.M.S.P.S., Régimen y Gobierno, Profesiones, lib. 16, p. 139. 
nobleza, como las de Petronila de Santa Teresa (28-VII-1751), ahijada de los marqueses de la Cueva del Rey ${ }^{43}$.

Otro dato relativo a la vida, o mejor a la muerte, de la monja es la nota necrológica que aparece en casi todas las cartas. Las primeras, iniciándose el siglo XVII, aparecen en la cara anterior, en el ángulo superior derecho, izquierdo o en todo el margen superior, $y$, más tarde, esta anotación pasa al reverso de la página. Algunas veces solo se dice "murió" ${ }^{4}$, otras se complementa la nota con la fecha de la defunción haciéndose cada vez más completa: "Murió a 5 de noviembre de 1663 siendo priora en él tres años" ${ }^{45}$. En los casos de mayor relevancia se consigna, además del día, la hora de su muerte, dónde está sepultada y se informa de sus cargos y su actividad dentro del monasterio. Buen ejemplo es la carta de Francisca de San Juan Bautista (25-I-1712), que murió el 17 de diciembre de 1771, fue priora durante tres trienios y está sepultada en la bóveda que está dentro del coro ${ }^{46}$.

Recogidos también en estas notas necrológicas aparecen acontecimientos históricos en los que Sevilla se vio inmersa y cuyos efectos afectaron al monasterio de Santa Paula. En la carta de María del Carmen (8-VII-1800), que murió el 11 de octubre de 1812, lo más interesante es la inscripción: "Lo ejemplar de su vida dio margen a que se señalase su cadáver poniéndole su nombre en un pergamino cosido en el Ávito y escapulario, fue muy [...] Caritativa que se privava de su alimento para dárselo a los Pobres especialmente en las necesidades que padeció esta comunidad en el tiempo de estar dominando las Andalucías los Exércitos franceses de cuyas resultas padeció y aún padecen mil necesidades las Religiosas" ${ }^{47}$. La nota muestra que el saqueo francés del general Soult no se limitó al aspecto artístico, sino que los ejércitos de ocupación se apoderaron también de los recursos económicos y alimenticios del cenobio. La profesa estuvo los dos últimos años de su vida intentando paliar los efectos que la ocupación francesa de Sevilla (1-II-18010/27-VIII-1812) causó concretamente en la comunidad de Santa Paula.

Pero dañar el monasterio tampoco fue exclusivo de ejércitos invasores, pues los nacionales también participaron en el destrozo. La inscripción en la carta de María de la Luz de San Luis Gonzaga (19-IV-1808) se refiere a otro

${ }^{43}$ SÁNCHEZ LÓPEZ, G.: "La música en los monasterios de monjas jerónimas...", op. cit., p. 954.

${ }^{44}$ Melchora de la Cruz (11-II-1618), Francisca de San Jerónimo (11-X-1637), Gerónima de San Juan (5-XII-1639). A.M.S.P.S., Régimen y Gobierno, Profesiones, lib. 15, ff. $1 \mathrm{r}, 58 \mathrm{r}$ y $61 \mathrm{v}$.

${ }^{45}$ Isabel de San Rafael (16-XI-1609). A.M.S.P.S., Régimen y Gobierno, Profesiones, lib. 14 , s. f.

46 A.M.S.P.S., Régimen y Gobierno, Profesiones, lib. 16, p. 161.

${ }^{47}$ A.M.S.P.S., Régimen y Gobierno, Profesiones, lib. 17, f. $21 \mathrm{v}$. 
acontecimiento político-militar: el bombardeo de Sevilla de 1843. Sitiada Sevilla por haberse posicionado en contra del gobierno de Espartero, el 18 de julio de 1843 el general Antonio Van Halen decide atacar y el 24 se inicia el bombardeo que duró unos días en los que cayeron 606 bombas y 900 balas rasas por Puerta de la Carne, Puerta Osario y la Calzada. Pero esta área se ve ampliada por la nota necrológica nueve años después (29-VII-1852) del bombardeo: "Fue [...] virtuosa principalmente en la caridad con sus hermanas a las que socorrió en tiempos de escasez y tribulación [...] reedificó la Yglesia de este Monasterio ruinosa a causa de las bombas del año de 1843 que cayeron tres de cuyo estremecimiento quedó el arco de la capilla mayor en estado de ruina; y tomó a su cargo ayudada de otras personas, reedificó el arco y armadura y reformó toda la Yglesia en cuya obra gastó de su peculio"48.

\section{ILUMINACIÓN}

No todas las cartas de profesión del monasterio de Santa Paula están iluminadas: las 98 del legajo 2 están únicamente escritas salvo alguna letra en tinta roja, de las 63 que contiene el libro 14 solo diez lo están levemente, de las 69 del libro 15 solo nueve están miniadas y cuatro más llevan ligeros toques de tinta, de las 167 del libro 1640 están iluminadas y algunas más se decoran con toques de tinta de color mientras que el libro 17 las tiene prácticamente todas, 118, iluminadas.

Los materiales usados son el papel para el soporte, la tinta negra para el texto y azul o roja para pequeños adornos, y la pintura al agua para la iluminación, como es habitual en los documentos miniados: libros, ejecutorias de hidalguía, reglas de cofradía, etc. Las cartas de profesión difieren mucho unas de otras por la amplitud de las ilustraciones, la habilidad con que están realizadas, la temática, que es bastante variada, y la cronología, pues la influencia de las tendencias artísticas del momento es inevitable, dado que de la primera de ellas a la última transcurren más de 360 años. Algunas de estas cartas muestran en sus temas y en la forma de ejecutarlos una habilidad que señala a los talleres de miniaturistas de la Sevilla del momento, mientras que otras, a veces copiando punto por punto las de gran calidad, no dejan de ser completamente caseras. Ni siquiera en el primer caso se suele encontrar la firma del autor. Casi una excepción en todos los aspectos, pues es de gran tamaño, el soporte es lienzo y la técnica es pintura al óleo, es la carta de profesión de María Josefa de Santa Gertrudis (Solís Folch de Cardona, 15-X-1767) del convento

48 A.M.S.P.S., Régimen y Gobierno, Profesiones, lib. 17, f. 30v. 
de las Comendadoras del Espíritu Santo de Sevilla, firmada por José Rubira ${ }^{49}$. En el monasterio de Santa Paula había dos cartas firmadas. Una de ellas era la desaparecida de Petronila de San Pedro realizada por el pintor Cornelio Schut entre octubre de 1682 y junio de 1683. La otra carta firmada es la de Agustina de San Pedro (3-VI-1685) ${ }^{50}$. El autor, Gijón, que coloca su diminuta firma en el borde inferior, ha realizado una espléndida iluminación con temas como la Virgen con el Niño, la Magdalena, San Pedro y San Agustín, en alusión al nombre de la profesa, dos columnas salomónicas y una gran cruz de Malta entre tarjas vegetales propias del siglo XVII (Figura 1). Las tarjas vacías en los ángulos inferiores de la página han quedado reservadas, presumiblemente, para las firmas, que finalmente no se hicieron allí, pero sí en la carta de Isabel del Buen Suceso (20-XI-1729) ${ }^{51}$.

El interés que han suscitado las cartas de profesión del monasterio de Santa Paula es escaso. Los integrantes del Laboratorio de Arte de la Universidad de Sevilla recogieron con sus cámaras una serie de imágenes de las que se conservan en su fototeca cinco positivos ${ }^{52}$ y un negativo ${ }^{53}$ realizado por Antonio Palau el 30 de noviembre de 1959. Medio siglo después, Álvaro Pastor en su estudio sobre la Inmaculada ${ }^{54}$ analiza seis cartas ${ }^{55}$ y reproduce un detalle de una de ellas. En los últimos años, José Carlos Vizuete y Francisco Javier Campos han ilustrado su obra ${ }^{56}$ con una de las cartas de profesión estudiadas por Álvaro Pastor. Así pues, de alrededor de 180 iluminadas, se han dado a conocer siete.

La mayoría de las cartas están únicamente escritas en tinta monocroma, con distintos tipos de letra y sin adorno alguno. Poco a poco la decoración se va introduciendo, primero a base de algún toque de tinta roja, para llegar pronto a cubrir

${ }^{49}$ FALCÓN, Teodoro et altera: La ciudad oculta. El universo de las clausuras de Sevilla. Sevilla, 2009, pp. 200-201.

${ }^{50}$ A.M.S.P.S., Régimen y Gobierno, Profesiones, lib. 16, p. 147.

${ }^{51}$ A.M.S.P.S., Régimen y Gobierno, Profesiones, lib. 16, p. 189.

52 Cartas de profesión de Brígida de la Corona (XII- 1656), Agustina de San Pedro (3VI-1685), María de Santa Clara (22-II-1693), María de las Mercedes (5-X-1710) e Isabel del Buen Suceso (20-XI-1729).

${ }_{53}$ Carta de profesión de Agustina de San Pedro.

${ }^{54}$ PASTOR TORRES, Álvaro: "Iconografía e iconología de la Inmaculada en el Monasterio de Santa Paula", en CAMPOS Y FERNÁNDEZ DE SEVILLA, Francisco Javier (coord.): Actas del congreso La Inmaculada Concepción en España. Vol. 2. San Lorenzo de El Escorial, 2005, pp. 935-964.

${ }^{55}$ Las de Beatriz de San Francisco (25-XI-1680), Ana de la Concepción (15-X-1682), María de Santa Clara (22-II-1693), María de los Ángeles Biñolas (6-VIII-1719), Gregoria de San Jerónimo (1-V-1730) y María Gloria de la Asunción (15-XII-1879).

56 VIZUETE MENDOZA, José Carlos y CAMPOS Y FERNÁNDEZ DE SEVILLA, Francisco Javier: Iluminaciones (La profesión religiosa y sus signos). San Lorenzo de El Escorial, 2013. 
el documento de elementos significativos que completan el sentido del texto. Aunque se imponga la iluminación en color, las cartas adornadas con ligeros temas en tinta negra siguen existiendo bien entrado el siglo XVII e incluso aparecen algunas posteriores cuya decoración, ya muy amplia, se realiza exclusivamente a plumilla en tinta, obteniendo resultados magníficos ${ }^{57}$.

La iluminación se realiza generalmente, además de en la letra inicial $\mathrm{Y}(\mathrm{o})$, en las cuatro márgenes del folio, en unas orlas que a veces ocupan un porcentaje de él importante. La carta de María de San Andrés (25-XI-1666) ${ }^{58}$, que tiene unas dimensiones de $216 \times 148 \mathrm{~mm}$, cuenta con las orlas superior e inferior de 35, aunque aún la superan otras cartas como la de Beatriz María de San Francisco (25-XI$1680)^{59}$.

La primera carta de profesión en donde aparece la tinta roja para destacar algo del texto es la de Úrsula de San Agustín (29-I-1484), en la que la inicial roja va sobre un fondo de finos dibujos azules, a la que sigue 40 años después la de Ynés de Sant Pedro (28-VI-1524) ${ }^{60}$ y la primera que podríamos considerar iluminada es la de Leonor de la Cruz (23-VIII-1581) ${ }^{61}$, muy casera pese a que por ser hija del marqués de Villamanrique no le faltarían los medios para que la hubiera hecho un profesional de la miniatura. En ella aparece por primera vez algún dibujito en el margen interior del folio que, pese a su sencillez, incluye un caracol, tema propio de la miniatura flamenca. Completa su escasa decoración la Y(o) de color amarillo oro sobre fondo azul. Con estos dos elementos inicia las primeras decoraciones de las cartas que van a consistir en orlas muy sencillas y realce de la letra capital, a veces usando únicamente tinta. La roja para destacar algunas capitales y para el enmarque aparece por primera vez en 1594, lo mismo que la roja y la azul enmarcando el folio por sus cuatro lados en esa bicromía propia del estilo llamado mudéjar ${ }^{62}$. Muy temprana es la aparición de los elementos decorativos en las cartas del monasterio benedictino de Santa Clara de Barcelona ${ }^{63}$, que ya desde el primer tercio del siglo XVI muestran letras capitales y ligeras orlas envolviendo el texto realizadas todavía en tinta pero que llevan ya color, imprescindible para su interpretación, en los escudos heráldicos de dichos documentos. En las cartas de profesión del convento de San Agustín de Barcelona la ornamentación

${ }^{57}$ Francisca de San Jerónimo (11-X-1637). A.M.S.P.S., lib. 15, f. 58r.

58 A.M.S.P.S., Régimen y Gobierno, Profesiones, lib. 16, p. 71

59 A.M.S.P.S., Régimen y Gobierno, Profesiones, lib. 16, p. 127.

${ }^{60}$ A.M.S.P.S., Régimen y Gobierno, leg. 2.

${ }^{61}$ A.M.S.P.S., Régimen y Gobierno, Profesiones, lib. 14, s. f.

${ }^{62}$ A.M.S.P.S., Régimen y Gobierno, Profesiones, lib. 14, s. f. Cartas de Quiteria de la Degollación (28-I-1594) y Ángela de San Pablo (6-X-1594).

${ }^{63}$ DARNA GALOBART, Leticia: "Heráldica en las cartas de profesión del monasterio de Santa Clara de Barcelona", Revistes Catalanes amb Accés Obert, RACO, 27, pp. 157-200. 
empieza en 1574 de una manera sencilla en la letra inicial y la orla ${ }^{64}$, mientras que en las de las del monasterio toledano de la Visitación, llamado de la Reina, que se encuentran en el de las jerónimas de Santa Marta de Córdoba, no se produce hasta $1695^{65}$. Aunque entre la primera fecha y la última citadas transcurren más de 200 años, los inicios de esa iluminación de las cartas siempre son los mismos: tinta, con toques ligeros en la letra inicial y en la orla.

Aparte de los temas decorativos existen en las cartas de profesión temas representativos que refuerzan su texto, de los que buena parte son alusivos a la orden jerónima. La cruz de Malta es el símbolo más repetido en las de Santa Paula. Por primera vez aparece, en el centro del margen superior, en las cartas de Leonor de San Agustín (12-I-1637) e Isabel de la Paz (12-II-1637) ${ }^{6}$. A partir de este momento la cruz de Malta se convierte en un elemento indispensable (Figura 2), 1legando a haber hasta seis ejemplares por documento, como en la carta de Catharina de Iesús (21-VI-1655) ${ }^{67}$.

Más temprana es la aparición, como elemento identificativo de la orden jerónima, del capelo cardenalicio, pues se ve por primera vez en la carta de Dionisia de San Andrés (28-III-1606) ${ }^{68}$, y del león y el capelo juntos en la de Gerónima de San Juan (5-XII-1639) ${ }^{69}$, y, poco después, en la de Petronila de la Presentación $(2-\mathrm{VII}-1674)^{70}$. Formando este tándem indisoluble se va a estar repitiendo en algunas cartas de los 340 años siguientes.

La figura misma de San Jerónimo es representada menos frecuentemente que los anteriores símbolos, pero ya aparece en las cartas de Teresa Francisca de Santa Rosa (15- VIII-1680) e Isabel de la Encarnación (10-XI-1680) ${ }^{71}$.

Representativa a la vez de la orden y del monasterio es la figura de Santa Paula (Figura 3), que aparece por primera vez, ya muy avanzado el siglo XVII, en la carta de Ana de la Concepción (15-X-1682) y se repite en las de María de Santa Clara (22-II-1693) y en la de Agustina de San Gerónimo (21-XI-1728)

Otro tema bastante usado es la plasmación gráfica de los votos de la regla que siguen los jerónimos, que es la de San Agustín. Aparece por primera vez en

${ }^{64}$ TORRA PÉREZ, Alberto: "Los libros de profesiones ilustrados del convento de San Agustín de Barcelona (siglos XV-XIX)", Memoria Ecclesiae, XVI, 2000, pp. 479-492.

${ }^{65}$ BENÍTEZ BLANCO, Vicente: "Santa Marta, un monasterio de monjas jerónimas en la Ajerquía de Córdoba”, en CAMPOS Y FERNÁNDEZ DE SEVILLA, Francisco Javier (coord.): Actas del congreso La clausura femenina en el mundo hispánico: una fidelidad secular. San Lorenzo de El Escorial, 2011, pp. 959-984 (975).

${ }^{66}$ A.M.S.P.S., Régimen y Gobierno, Profesiones, lib. 15, ff. 56 y 56v.

${ }^{67}$ A.M.S.P.S., Régimen y Gobierno, Profesiones, lib. 16, p. 45.

${ }^{68}$ A.M.S.P.S., Régimen y Gobierno, Profesiones, lib. 14, s. f.

${ }^{69}$ A.M.S.P.S., Régimen y Gobierno, Profesiones, lib. 15, f. 61v.

70 A.M.S.P.S., Régimen y Gobierno, Profesiones, lib. 16, p. 74.

${ }^{71}$ A.M.S.P.S., Régimen y Gobierno, Profesiones, lib. 16, pp. 123 y 125.

72 A.M.S.P.S., Régimen y Gobierno, Profesiones, lib. 16, pp. 139, 151 y 187. 
la carta de Leonor de Santa Catalina (28-III-1606) ${ }^{73}$, en la que en un corazón que acoge el texto hay atravesadas cuatro flechas en las que se lee pobreza, obediencia, clausura y castidad. Son las mismas cuatro reglas que, esta vez en las esquinas de una cuidadosa orla vegetal, están recogidas en la de María Baptista (13-IV$1608)^{74}$. Pese a este origen tan temprano, no vuelve a aparecer el tema hasta casi 200 años después en la carta de Antonia María de la Presentación (2-VI-1800) ${ }^{75}$, en la que las cuatro esquinas de la amplia orla vegetal están ocupadas por pájaros que llevan en el pico una filacteria con el nombre de los votos. A partir de este momento, las fórmulas para hacerlos patentes se suceden, plasmadas en un libro abierto, en doce cartas más que llegan hasta $1828^{76}$. Un buen ejemplo de ellas es la de Ramona María de la Concepción (25-III-1827) (Figura 4) ${ }^{77}$.

Es bastante frecuente, como ocurre en monasterios tanto jerónimos como de otra orden, que los santos titulares de la profesa aparezcan representados entre los temas de las cartas de profesión. Los ejemplos se suceden a lo largo del tiempo. La magnífica carta de Brígida de la Corona (XII-1656) lleva dos angelitos sujetando una corona, la de María de San Andrés (25-XI-1666) a este santo, la de Susana de San Agustín (21-IV-1678) a estos dos santos, la de Teresa Francisca de Santa Rosa (15-VIII,-1680) a las dos santas, la de Isabel del Buen Suceso (20IX-1729) a Santa Isabel de Hungría ${ }^{78}$ (Figura 5). Alguna vez los santos representados están aludiendo al nombre de los padres de la monja, como es el caso de la carta de Agustina de San Gerónimo (21-XI-1728)79, que además de sus dos santos patronos incluye a San José por su madre, Josefa Hornillos de Rueda. También se alude a los nombres de las profesas por símbolos, como el anagrama de Cristo de la de Teresa de Jesús (23-XII-1669), el cáliz y la hostia de la de Bernardina del Santísimo Sacramento (14-VI-1683) o por escenas como la de la Anunciación, con el jarrón de lirios incluido, en la de Isabel de la Encarnación (10-XI-1680) ${ }^{80}$.

${ }^{73}$ A.M.S.P.S., Régimen y Gobierno, Profesiones, lib. 14, s. f.

${ }^{74}$ A.M.S.P.S., Régimen y Gobierno, Profesiones, lib. 14, s. f.

75 A.M.S.P.S., Régimen y Gobierno, Profesiones, lib. 17, f. 19r.

${ }^{76}$ Cartas de profesión de María del Carmen (8-VI-1800), Florentina María de la Asunción (1-II-1802), María de San José (29-VI-1802), María del Coral (4-VII-1802), Gertrudis de los Dolores (3-X-1802), Leonarda de San Rafael (23-XI-1803), Juana del Amparo de la Visitación (8-IV-1804), María de la Salud (24-V-1804), Saturnina de los Ángeles (8-VI-1804), María de la Luz de San Luis Gonzaga (19-IV-1808), Ramona María de la Concepción (25-III-1827) y María de los Dolores de la Santísima Trinidad (10-II-1828). A.M.S.P.S., Régimen y Gobierno, Profesiones, lib. 17, ff. 20r, 22r, 23r, 24r, 25r, 26r, 27r, 28r, 29r, 30r, 33r y 34r.

77 25-III-1827. A.M.S.P.S., Régimen y Gobierno, Profesiones, lib. 17, f. 33r.

78 A.M.S.P.S., Régimen y Gobierno, Profesiones, lib. 16, pp. 47, 71, 115, 123 y 189.

79 A.M.S.P.S., Régimen y Gobierno, Profesiones, lib. 16, p. 187.

${ }^{80}$ A.M.S.P.S., Régimen y Gobierno, Profesiones, lib. 16, pp. 85, 143 y 125. 
Estos temas significativos, junto a los que representan las devociones particulares de las profesas, son impuestos a los autores por el monasterio, pero los decorativos, que actúan como hilo conductor, son elegidos por los escribanos-miniaturistas que realizan las cartas y van reflejando, en general con bastante retraso, las corrientes artísticas del momento. Así, las decoraciones en tintas rojas y azules, propias del llamado estilo mudéjar, usado desde fines de la Edad Media, pero vigente mucho tiempo después, lo vemos aparecer en orlas como la que rodea por los cuatro lados el texto de la carta de María de San José (5-V$1601)^{81}$. Los temas góticos de lentejuelas con cilicios, recurrentes de forma especial durante la segunda mitad del siglo XV, se ven en la carta de Teresa de Jesús $(23-X I I-1669)^{82}$. Procedentes del estilo flamenco, que arranca en nuestro país hacia el 1500, pero que se va a estar vigente hasta muy entrado el siglo XVII, aparece un caracol en la ligera orla de la carta de Leonor de la Cruz (23-VIII-1581) y muchas mariposas y moscas en la de Flor Margarita de San José (29-X-1674) ${ }^{83}$. Poco impacto tienen los temas propios del Renacimiento, pues solo en el caso de la carta de María de San Antonio (27-XII-1791) ${ }^{84}$ se ven elementos paganos como son los putti. La miniatura del siglo XVII muestra su influencia en las cartas de profesión de Santa Paula a través, principalmente, de unas hojas trilobuladas de vivos colores muy matizados que forman una orla envolvente del texto, acogiendo entre ellas los temas significativos, pero que tienen un gran protagonismo, como vemos en la carta de Isabel de la Encarnación (10-XI-1680) ${ }^{85}$. Durante el siglo XVIII todavía se mantienen vigentes, según se aprecia en la carta de Gregoria de San Gerónimo (1-V-1730) ${ }^{86}$. También son una aportación de la miniatura del siglo XVII, con el mismo cromatismo de las hojas, unas cartelas alabeadas, cuyos bordes se enroscan sobre sí mismos. Muy a fines del siglo XVIII se aprecia un radical cambio de ornamentación. Las anchísimas orlas cargadas de temas significativos dejan paso con frecuencia a otras más finas y sencillas que incorporan a veces elementos geométricos, como la de la carta de Bernardina de la Santísima Trinidad (5-XII-1790) ${ }^{87}$. En la de Joaquina de Nuestra Señora de Todos los Santos (2-II-1791 $)^{88}$ aparece por primera vez la rocalla, algunos años después de que se viera en 1778 en el monasterio jerónimo de la Visitación de Toledo ${ }^{89}$. También

${ }^{81}$ A.M.S.P.S., Régimen y Gobierno, Profesiones, lib. 14, s. f.

82 A.M.S.P.S., Régimen y Gobierno, Profesiones, lib. 16, p. 83.

3 A.M.S.P.S., Régimen y Gobierno, Profesiones, libs. 14, s. f. y 16, p. 101.

${ }^{84}$ A.M.S.P.S., Régimen y Gobierno, Profesiones, lib. 17, f. 4r.

${ }^{85}$ A.M.S.P.S., Régimen y Gobierno, Profesiones, lib. 16, p. 185.

${ }^{86}$ A.M.S.P.S., Régimen y Gobierno, Profesiones, lib. 16, p. 191.

87 A.M.S.P.S., Régimen y Gobierno, Profesiones, lib. 17, f. 1r.

${ }^{88}$ A.M.S.P.S., Régimen y Gobierno, Profesiones, lib. 17, f. 2 r.

89 BENÍTEZ BLANCO, V.: "Santa Marta, un monasterio de monjas jerónimas...", op. cit., p. 976. 
en estos momentos reaparecen unos cortinajes recogidos a un lado y otro por ramos de flores y una corona arriba (Manuela de Jesús, 6-I-1792, y Victoria de San Juan, 5-II-1797) ${ }^{90}$, tema que tiene ya 150 años de antigüedad (Francisca de San Gerónimo, 11-X 1637) ${ }^{91}$. Muy novedosos de los momentos finales del siglo XVIII son los escenarios arquitectónicos como enmarque del texto, unas veces con columnas jónicas y frontón curvo simulando un altar o el frontispicio de un libro (Mariana de la Pasión, 28-VI-1798) y otras veces con columnas corintias (Juana del Amparo de la Visitación, 8-IV-1804) ${ }^{92}$.

Las cartas iluminadas muestran una muy distinta habilidad y soltura de ejecución evidenciando la capacidad del autor. En algunas de ellas se ve la mano de un escribano-íluminador al que con frecuencia recurren en Santa Paula. Este es el caso de la magnífica carta de María de las Mercedes (5-X-1710) ${ }^{93}$, cuya anchísima orla acoge, arriba, al Cordero Místico, a los lados, a cuatro angelitos en graciosas actitudes y, debajo, otros dos sosteniendo una cartela con el capelo cardenalicio (Figura 6). Del mismo tipo, prácticamente con los mismos temas y el mismo brillante colorido es la carta de Francisca de San Juan Bautista (25-I-1712) ${ }^{94}$ (Figura 7). Estos documentos realizados por buenos miniaturistas tuvieron, con bastante frecuencia, imitaciones caseras, poco hábiles. Este es el caso de la carta de Josefa de San Francisco (10-X-1719) ${ }^{95}$ que, basándose en las dos anteriormente citadas, produce una pobre impresión. El taller de miniaturistas al que se recurre suele hacer varios trabajos seguidos en fechas más o menos próximas, tal como ocurre en el monasterio toledano de la Reina, en cuyas cartas se aprecia una coincidencia de autor y de diseño ${ }^{96}$.

En el monasterio de Santa Paula una serie de cartas de entre 1637 y 1641 muestran una identidad de ejecución que apunta a una misma mano. Inicia la serie la carta de Leonor de San Agustín (12-I-1637) ${ }^{97}$, todavía muy sencilla, pero que ya muestra el color rojo y los temas de fondo que se van a desarrollar en las siguientes. La de Isabel de la Paz (12-II-1637) ${ }^{98}$ es una auténtica explosión de color, rojos, azules, verdes y rosas, con las hojas características de la miniatura del siglo XVII y, como elemento de relleno, unas especies de espigas agitadas por el viento que, en ocasiones, son doradas. Como elementos significativos únicamente

90 A.M.S.P.S., Régimen y Gobierno, Profesiones, lib. 17, ff. $5 \mathrm{r}$ y $11 \mathrm{r}$.

91 A.M.S.P.S., Régimen y Gobierno, Profesiones, lib. 15, f. 58r.

92 A.M.S.P.S., Régimen y Gobierno, Profesiones, lib. 17, ff. 15r y $27 \mathrm{r}$.

93 A.M.S.P.S., Régimen y Gobierno, Profesiones, lib. 16, p. 153.

94 A.M.S.P.S., Régimen y Gobierno, Profesiones, lib. 16, p. 161.

95 A.M.S.P.S., Régimen y Gobierno, Profesiones, lib. 16, p. 179.

96 BENÍTEZ BLANCO, V.: "Santa Marta, un monasterio de monjas jerónimas...", op. cit., pp. 976 y 977.

97 A.M.S.P.S., Régimen y Gobierno, Profesiones, lib. 15, f. 56r.

98 A.M.S.P.S., Régimen y Gobierno, Profesiones, lib. 15, f. 56v. 
aparecen la cruz de Malta, en la parte superior de la orla, y una inscripción latina del salmo 115, en la inferior, ambos dentro de una cartela alabeada (Figura 2). Siguiendo las mismas pautas, con los mismos elementos decorativos, está la de Gerónima de San Juan (5-XII-1639)99, en la que el centro de la orla superior está ocupado por el Cordero Místico con la cruz en banderola, los lados por cruces de Malta y el inferior por el león y el capelo cardenalicio. Prácticamente idéntica es la carta de Ana de la Asunción, de la misma fecha que la de su hermana, la profesa anterior, cuyo único cambio es colocar en la parte superior de la orla la cabeza cortada del Bautista, en homenaje a su padre Juan Bautista de Mendoza y en la inferior la cabeza de un angelito dentro de una cartela ${ }^{100}$. Las cartas de otras dos hermanas, Isabel de San Diego (Figura 8) y Mariana de San Pedro (Figura 9), que profesaron juntas el 28 de agosto de $1641^{101}$, repiten exactamente temas, colores, extensión de la iluminación, predominio de los elementos decorativos y parquedad de los significativos.

El autor de estas seis cartas es el mismo que realizó la iluminación de la $R e$ gla de la insigne Cofradía del Dulcísimo Iesus Nazareno y sanctíssima Cruz de Ierusalen... Año de 1642. Las cartelas que contienen el título de la cofradía y la cruz de Jerusalén ${ }^{102}$ se enrosca igual y tiene los mismos colores que la de la carta de Mariana de San Pedro en la que la letra capital Y(o) es igual a las que inician los capítulos de la regla. En ambos documentos los fondos están ocupados por las mismas palmetas o espigas que parecen agitarse por el viento y además coinciden sus fechas de ejecución (Figura 10). Los mismos elementos decorativos se encuentran en otras reglas de cofradías como la de la Santísima Veracruz que fue iluminada por Juan de Herrera en $1631^{103}$, algunas de cuyas páginas, especialmente las que inician los capítulos, se asemejan mucho a las seis cartas de profesión citadas, tanto por la distribución de la decoración como por el tamaño parecido. Hay otras reglas, como la de la cofradía de la Virgen del Rosario de Sanlúcar de Barrameda, y otros documentos iluminados que proceden de este activo taller miniaturista sevillano.

Estas seis cartas de profesión de entre 1637 a 1641 están también vinculadas a algunos libros de coro de la catedral de Sevilla. El libro 21, que fue realizado en 1636 bajo la dirección del maestro de ceremonias Sebastián Vicente Villegas, lleva una miniatura cuyo centro está ocupado por el busto de Santa Isabel de

\footnotetext{
${ }^{99}$ A.M.S.P.S., Régimen y Gobierno, Profesiones, lib. 15, f. $61 \mathrm{v}$.

100 A.M.S.P.S., Régimen y Gobierno, Profesiones, lib. 15, f. 62r.

101 A.M.S.P.S., Régimen y Gobierno, Profesiones, lib. 15, ff. 67v y $68 \mathrm{r}$.

102 Folios 1r y $2 \mathrm{v}$.

${ }^{103}$ LAGUNA PAÚL, Teresa: "Juan de Herrera y las reglas de la cofradía de la Veracruz. Una contribución al estudio de la miniatura sevillana de siglo XVII", Laboratorio de Arte, 8, 1995, pp. 127-156.
} 
Portugal $^{104}$. La cartela en la que se aloja es igual a las descritas anteriormente: una cartela arquitectónica que se enrosca completándose con elementos vegetales, especialmente las hojas trilobuladas. El fondo de toda la miniatura está ocupado por esas espigas doradas. Todos los elementos son los habituales en la miniatura del siglo XVII y más en concretamente en la primera mitad. El libro 102, de 1629. 1630, auspiciado como tantos otros por Sebastián Vicente Villegas, contiene una letra $\mathrm{S}^{105}$ de gran tamaño, de las mismas características que estamos analizando y fue escrito por Andrés Camacho, que dejó en el libro, como era frecuente en él, sus iniciales. Este escribano está trabajando para la catedral desde 1614 adecuando los libros de coro de los siglos XV y XVI al nuevo rezado romano, impuesto desde el Concilio de Trento, pero además haciendo libros nuevos. No solo escribe, sino que gestiona toda la tarea de fabricación del libro, ilumina, como lo demuestra el que reciba pagos por ello ${ }^{106}$ y encuaderna dentro y fuera de la catedral, pues tiene montado un taller, documentado ${ }^{107}$, del que salen muchas obras. De entre ellas destaca, para el caso que nos ocupa, haber escrito el texto de la regla de la cofradía de la Veracruz ${ }^{108}$. Los caracteres de esta escritura, gótica textual redondeada, son exactamente los mismos que los de la cofradía de Jesús Nazareno, por lo que también la escribió él.

El mismo taller sigue realizando cartas con pocas modificaciones en los años siguientes, como se aprecia en las de Juana de la Degollación (1-IX-1642), Catharina de Iesus (21-VI-1655) y María de San Andrés (25-XI-1666), y todavía algún tiempo después dos cartas, las de María de San Rafael y Catalina de Sena (ambas de 29-XII-1680) ${ }^{109}$, continúan en parte esas mismas pautas.

Algunas cartas de profesión, además de usar los mismos temas, tener un aire semejante e incluso denotar una misma mano, llegan a ser un auténtico calco unas de otras. Este es el caso de la de María de Santa Clara (22-II-1693), que es una copia exacta (Figura 3) de la de Ana de la Concepción (15-X-1682) ${ }^{110}$, hija del escultor y retablista Francisco Dionisio de Ribas y de su mujer Laura Trujillo. La composición, los colores, los elementos decorativos y los significativos en su mayoría son los mismos y eso que entre una y otra median casi once años. El texto está encajado en una especie de óvalo formado por tarjas, hojas y flores al que se adosan ocho

${ }^{104}$ Folio 0r.
${ }^{105}$ Folio 1v.
${ }_{106}$ Por dos letras iluminadas. Archivo Catedral de Sevilla (A.C.S.), sección VI, lib. 06320 (625-627), nómina tercera de julio de 1637.

107 Archivo Histórico Provincial de Sevilla (A.H.P.Se.), sección Protocolos Notariales de Sevilla, Protocolo 2507 , libro $1^{\circ}$ de 1622 , ff. $717 \mathrm{v}$ y $718 \mathrm{r}$.

${ }^{108}$ LAGUNA PAÚL, T.: "Juan de Herrera y las reglas de la cofradía de la Veracruz...", op. cit., p. 130.

109 A.M.S.P.S., Régimen y Gobierno, Protocolos, lib. 16, pp. 1, 45, 71, 129 y 131.

110 A.M.S.P.S., Régimen y Gobierno, Profesiones, lib. 16, pp. 151 y 139. 
espacios formados por tarjas y guirnaldas vegetales alternativamente. Mientras las tarjas y hojas trilobuladas son semejantes a las que se han estado usando durante el siglo XVII, las guirnaldas de flores están ya preludiando los nuevos modelos de orlas que serán frecuentes más adelante. En la carta de María de Santa Clara se mantienen las figuras de San Jerónimo, la Inmaculada, San José en la parte superior de la orla y San Juan Bautista y Santa Paula en la inferior, pero sustituye a Santa Ana y San Joaquín, que existían en la carta de Ana de la Concepción, en las orlas laterales, por el arcángel San Miguel y Santa Teresa de Jesús y en la orla inferior a San Francisco por San Juan Evangelista.

Fecha de recepción: 24 de octubre de 2016

Fecha de aceptación: 4 de enero de 2017 


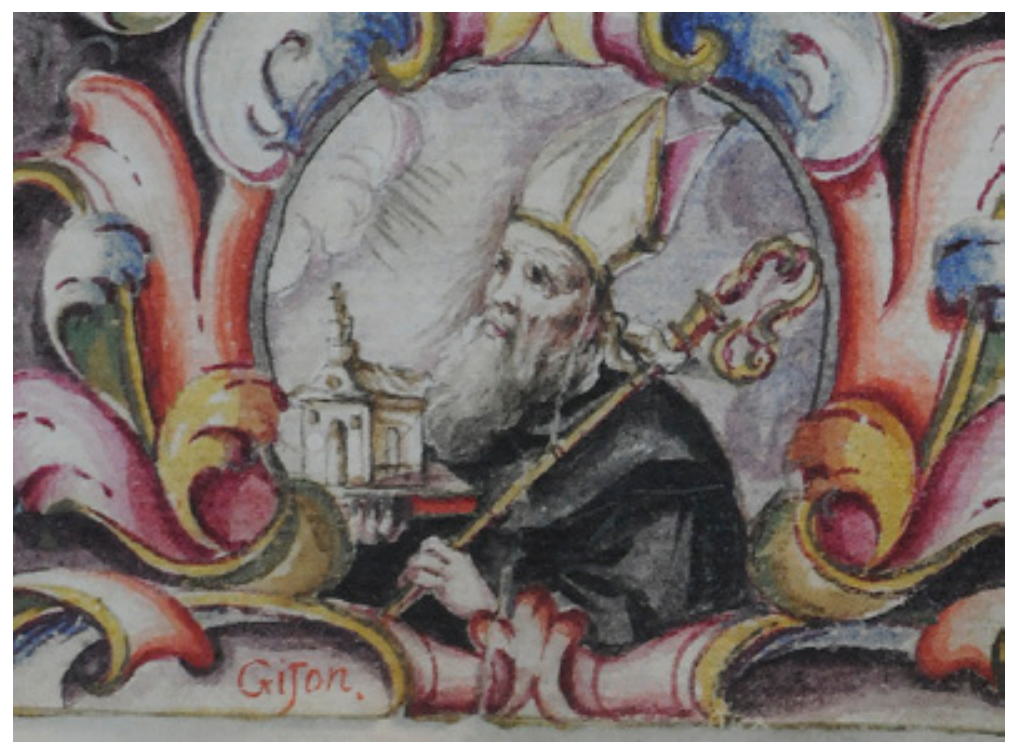

Figura 1. Carta de profesión de Agustina de San Pedro (detalle con la firma del autor), 3-VI-1685.

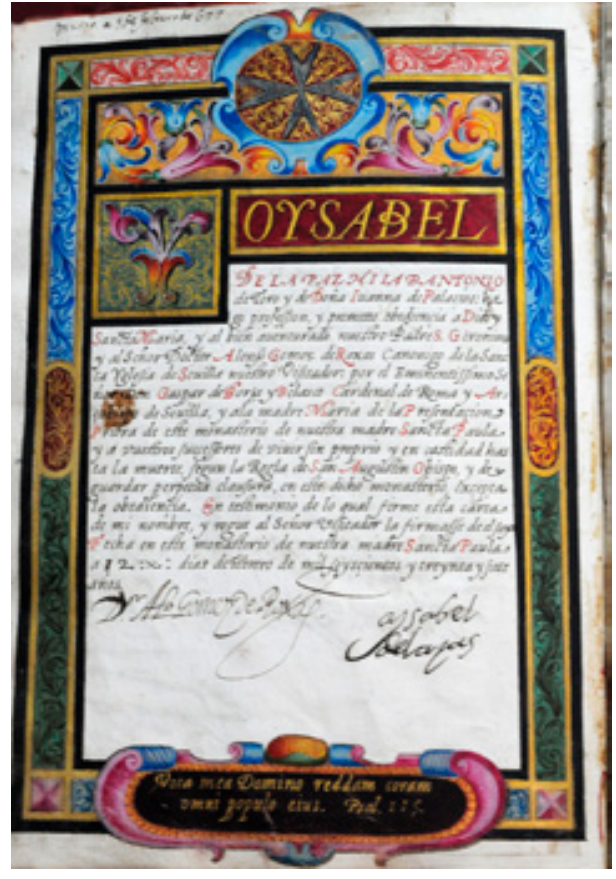

Figura 2. Carta de profesión de Ysabel de la Paz, 12-II-1637. 
Figura 3. Carta de profesión de María de Santa Clara, 22-II-1693.

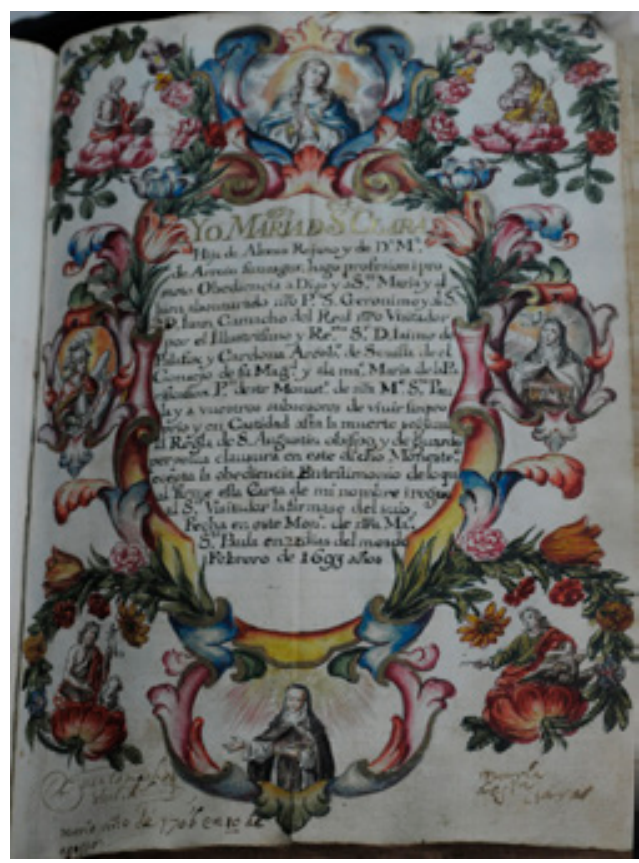

Figura 4. Carta de profesión de Ramona María de la Concepción, 25-III-1827.

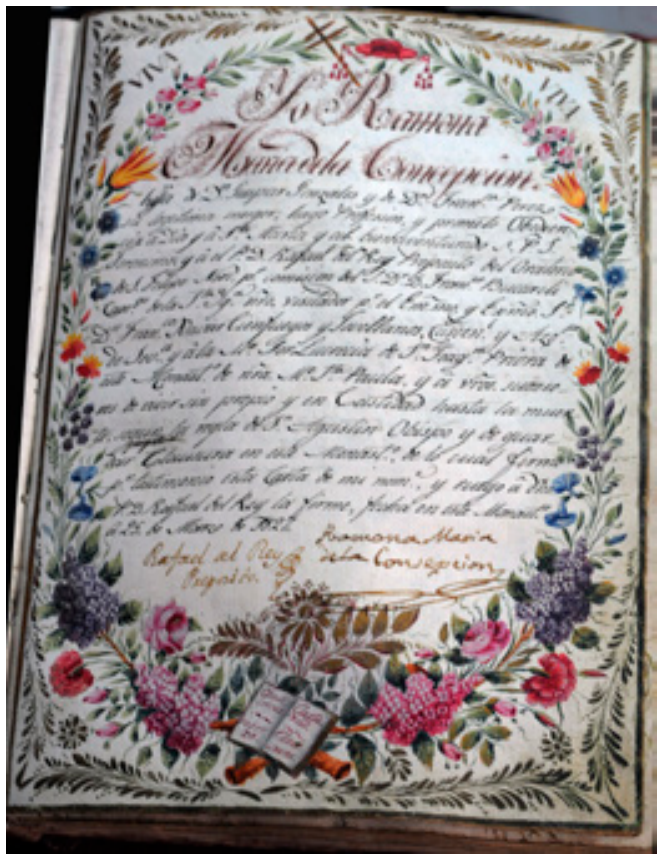

LABORATORIO DE ARTE 29 (2017), pp. 83-106, ISSN 1130-5762 e-ISSN 2253-8305 - DOI http://dx.doi.org/10.12795/LA.2017.i29.04 

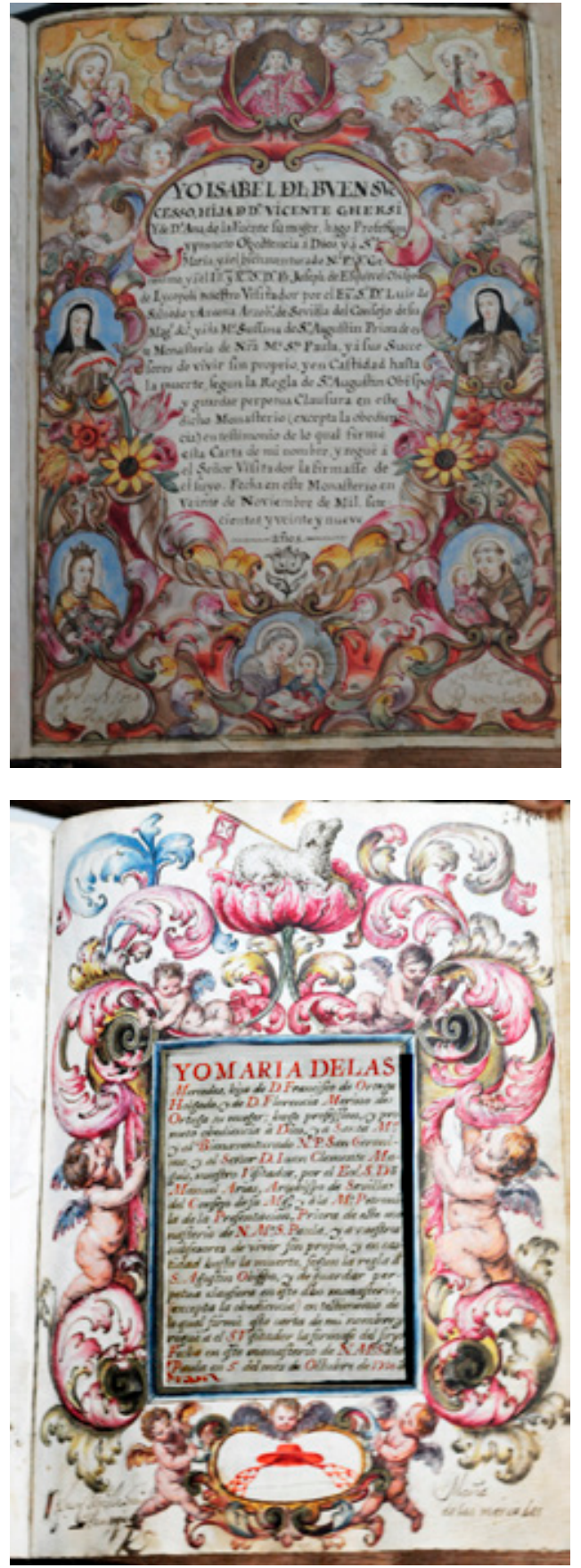

Figura 5. Carta de profesión de Isabel del Buen Suceso, 20-IX-1729.
Figura 6. Carta de profesión de María de las Mercedes, 5-X-1710. 
Figura 7. Carta de profesión de Francisca de San Juan Bautista, 25-I-1712.
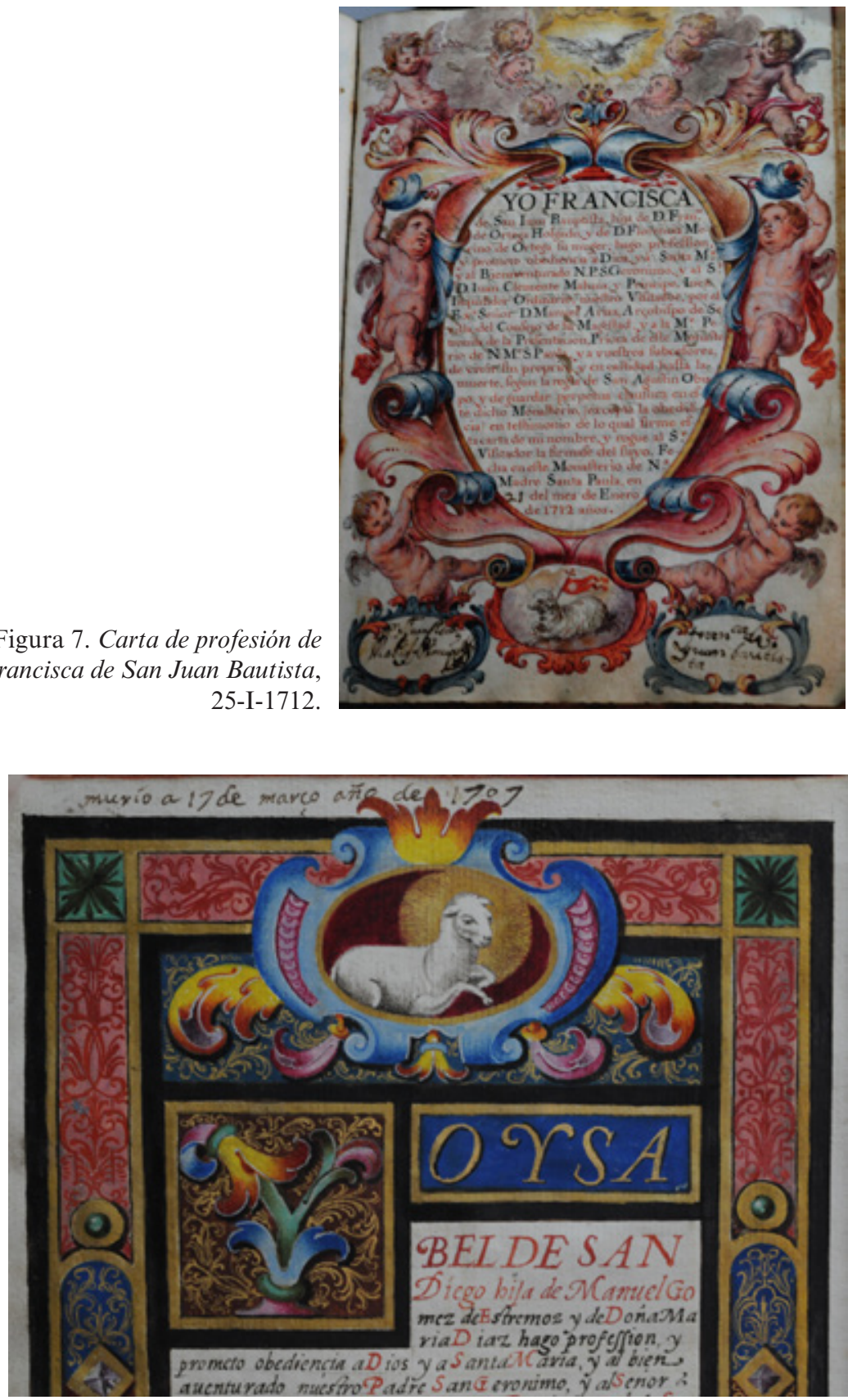

Figura 8. Carta de profesión de Isabel de San Diego, 28-VIII-1641.

LABORATORIO DE ARTE 29 (2017), pp. 83-106, ISSN 1130-5762 e-ISSN 2253-8305 - DOI http://dx.doi.org/10.12795/LA.2017.i29.04 


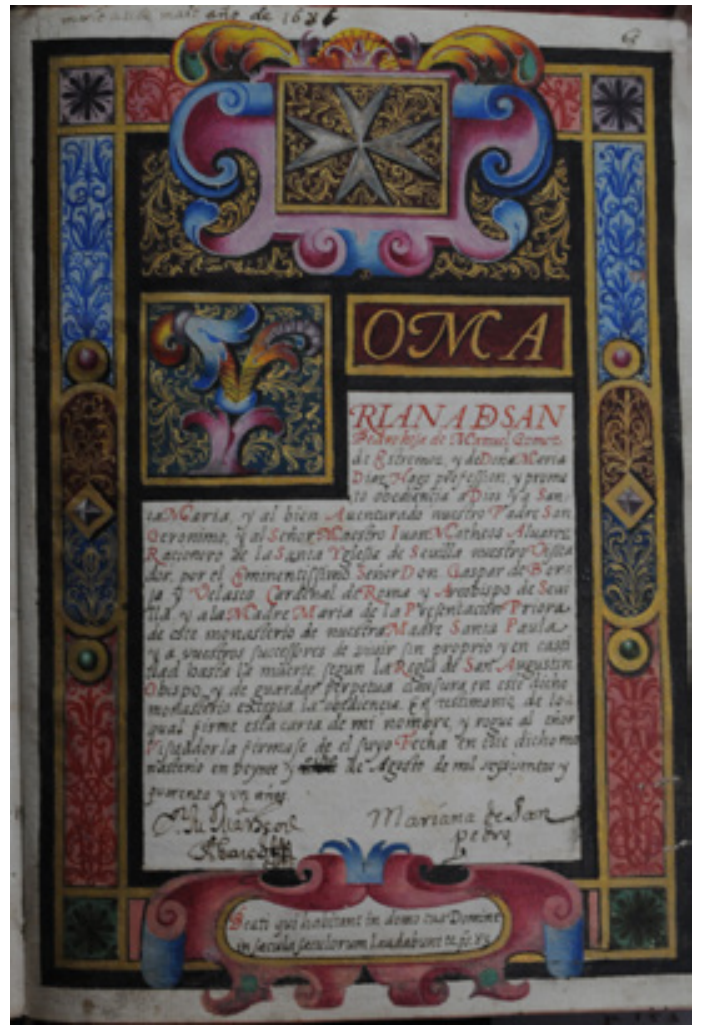

Figura 9. Carta de profesión de Mariana de San Pedro, 28-VIII-1641.

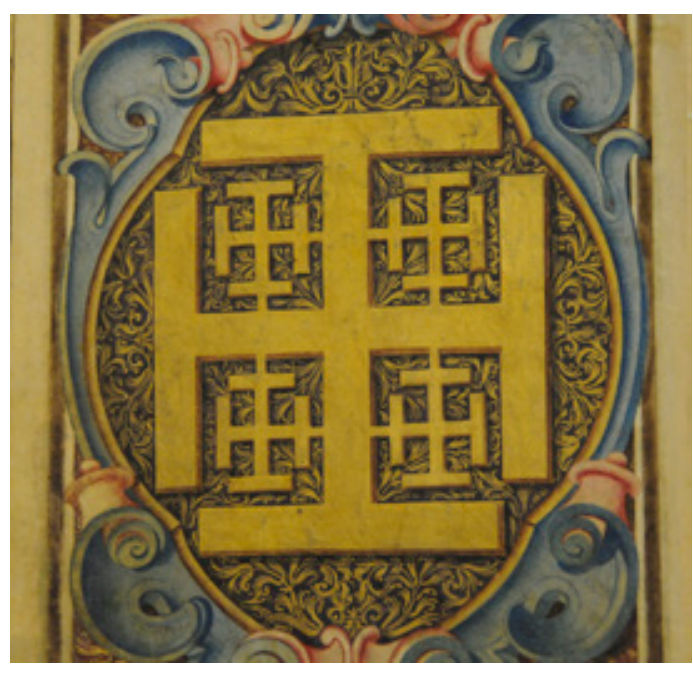

Figura 10. Regla de la Insigne Cofradía del Dulcísimo Jesús Nazareno y Santísima Cruz de Jerusalén, 1642, f. $2 \mathrm{v}$. 